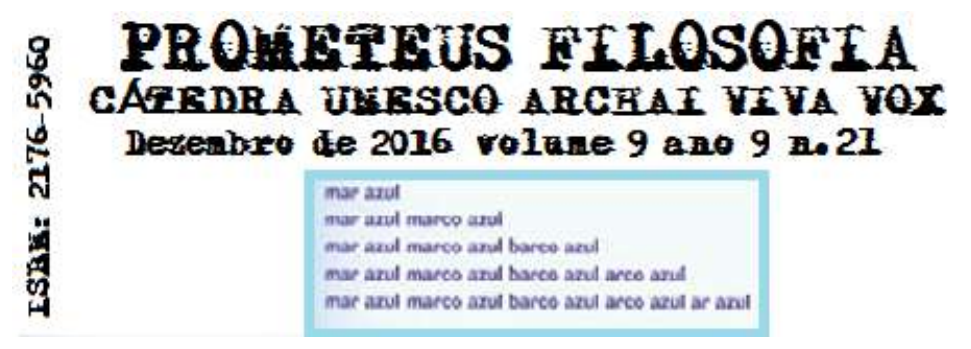

\title{
SE NÃO HÄ UM...: \\ A RELAÇÃO DO OUTRO COM O OUTRO NA SÉTIMA TESE DA SEGUNDA HIPÓTESE DO PARMÊNIDES DE PLATÃO
}

\author{
Gabriele Cornelli \\ Cátedra UNESCO Archai \\ Programa de Pós-Graduação em Metafísica (PPG $\mu / \mathrm{UnB})$ \\ Departamento de Filosofia, Universidade de Brasília
}

\begin{abstract}
RESUMO: O presente ensaio tem como objetivo examinar o problema colocado na Sétima Tese da Segunda Hipótese do Parmênides de Platão (164b-165E). A citada hipótese centra-se na relação dos outros com o outro, voltando assim para a Terceira Tese, mas, desta vez, sem o apoio do Um para impedir a fragmentação. Assim, toda a percepção da realidade sofre um processo de deriva, descrito por Parmênides como "um sonho durante o sono", no qual cada um dos outros "de Um que parecia se revela multíplice, de pequeníssimo um todo enorme" (164d). O sonho, no entanto, apresenta características muito precisas destes conjuntos: entre elas, o fato de "ter o número" (164d) e "aparecer no seu interior o par e o ímpar" (164e). O "sonho numérico" de Parmênides pode ser uma importante chave de leitura para compreender a consistência histórico-teórica da Sétima Tese, especialmente quando visto à luz do debate ontológico e matemático que ocupa o Quinto Século, antes de Platão.
\end{abstract}

PALAVRAS-CHAVE: Platão. Parmênides. Segunda Hipótese. Ontologia. Sonho.

ABSTRACT: This paper aims to examine the problem posed in the Seventh Thesis of the Second Hypothesis of Plato's Parmenides (164b-165e): the hypothesis focuses on the relationship of the other with the other, thus returning to the Third Thesis but, this time, without the support of the One in order to stop to the fragmentation. So, the whole perception of reality is subjected to a process of drift which is described "as in a dream during sleep" - says Parmenides - each one of the others "from one reveals itself multiple and from small huge" (164d). The dream, however, introduces very precise characteristics of these wholes, including the fact of "having the number" (164d) and that they "appear inside the even and the odd" (164d). This "numerical dream" of Parmenides can be an important key to understand the historical and theoretical consistency of the Seventh Thesis, especially in the context of the Fifth Century ontological and mathematical debate, i.e. before Plato.

KEYWORDS: Plato. Parmenides. Second Hypothesis. Ontology. Dream. 


\section{Introdução}

O propósito deste ensaio é aquele de procurar, por trás do texto platônico, o desenho de um diálogo de Platão com seus predecessores ${ }^{1}$. É, portanto, neste contexto maior que as indagações aqui contidas devem ser compreendidas. Os limites da leitura do Parmênides de Platão aqui propostos, portanto, coincidem com os limites da investigação pretendida.

Em linhas gerais, é certamente o caso de concordar com Migliori quando ele refere que o Parmênides não deve ser compreendido simplesmente como confrontação agônica de Platão com outras escolas de pensamento antigo. O diálogo é, antes de mais nada, um texto acadêmico que funcionava, da mesma maneira que os outros diálogos, como palestra teorética para o debate da escola platônica. Assim nota Migliori:

non é discussione erudita o semplice confronto con altre scuole, ma é autodisvelamento della propria formazione teoretica, la quale risulta assai più complessa di quanto i moderni e i contemporanei hanno generalmente riconosciuto (MIGLIORI, 1990, p. 411).

Todavia, este confronto com as outras escolas ou mesmo com os predecessores (como os de matriz eleática) pode ser compreendido melhor quando imaginado como algo ainda interno à própria Academia. Esta é a sugestão fundamental das páginas a seguir. Isso significa afirmar que os diálogos, e o Parmênides incluído, sejam mais do que uma espécie de propedêutica ao "tormento do pensamento": tal era a proposta de Gentile para justificar o ensino da história da filosofia em seus célebres programas ministeriais italianos. Pode-se, ao contrário, afirmar mais propriamente que zenonianos e pitagóricos estavam todos lá, sentados nos bancos da Academia, por assim dizer ${ }^{2}$. Os fragmentos dos primeiros acadêmicos não parecem deixar muitas dúvidas neste sentido. O debate com os predecessores assume, portanto, conotações de uma urgência que, bem longe de mero exercício antiquário (ou, pior, sofístico), configura-se como um

\footnotetext{
${ }^{1} \mathrm{O}$ presente artigo foi originalmente apresentado no II Congresso da Secção Mediterrânea da International Plato Society: o Parmênides de Platão (Coimbra, 14-16/06/2012). O texto aqui publicado é uma versão revista e atualizada do mesmo.

${ }^{2}$ Vejam-se neste sentido os estudos de Margherita Isnardi-Parente, especialmente de 1979, e sua edição dos fragmentos de Espeusipo e Xenócrates (1980 e 1982).
} 
confronto interno com as correntes de pensamento que se articulavam no interior da Academia $^{3}$.

Este confronto com os predecessores assume um significado ainda mais importante se consideramos que, na lógica da léxis, isto é, da ordem dramática dos diálogos, o Parmênides seria o primeiro diálogo de Platão (ERLER, 2012).

\section{Se não há Um}

Para desvendarmos este horizonte hermeneûtico, temos primeiro de analisar de perto a passagem da Sétima tese, ou melhor, da terceira série de deduções relativas à Segunda Hipótese (H2D3, passagem 164b-165e).

A referida passagem se propõe a examinar as consequências para os outros, quando considerados em relação ao Um, na hipótese deste não ser:

Vamos dizer então, se não há Um, quais consequências isso deve ter sobre os outros. (Parm.164b) ${ }^{4}$

No momento em que o Um não é, os outros não admitem propriamente determinações ontológicas, mas somente aparências. De fato, o léxico das aparências parece tomar aqui conta da série de deduções (FERRARI, 2004, p.118). Mais do que a uma possível referência implícita, com este léxico, à segunda parte do poema de Parmênides (MORAVCSIK, 1992, p.157), chama atenção quanto à conexão deste léxico do aparecer com uma imagem - também presente na página - que é aquela do sonho. Verifica-se haver de fato uma rede lexical bem arrumada a sustentar as deduções e o sentido desta rede lexical ficará evidente a seguir.

A longa lista de consequências, de deduções da hipótese de que o Um não seja, inicia-se significativamente com uma referência à linguagem, como bem viu Cornford (1939, p.235): aqui Parmênides assume, primeiramente, o significado de "o Um não é"

\footnotetext{
${ }^{3}$ Não conheço qualquer trabalho dedicado especificamente à Academia durante os anos de vida de Platão. Tentei eu mesmo esboçar recentemente um estudo do problema (CORNELLI 2016). Para uma ideia de como os discípulos mantinham posições teoréticas bastantes distintas, bastaria citar o próprio Aristóteles, que somente aos 41 anos deixa a Academia, à morte de Platão, para seguir um percurso intelectual bastante distinto de acadêmicos como Espeusipo e Xenócrates. Veja-se também CHERNISS (1945) e DILLON (2003).

${ }^{4}$ Todas as traduções de textos antigos são de minha autoria, caso contrário será referido na primeira ocorrência.
} 
como significando mais precisamente o seguinte: "suponhamos que não exista nada que possa ser chamado de alguma coisa”. A suposição da linguagem permite a Parmênides

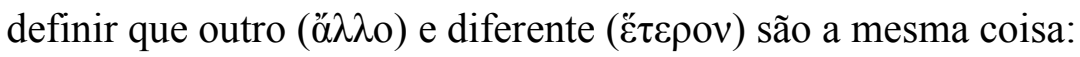

De fato, não chamas a mesma realidade de outro e diferente? (Parm.164b-c).

Cornford traduz a passagem de forma bem mais ousada, mas, segundo me parece, substancialmente correta: "'other' and ' different' are two names for the same thing" (1939, p.236). A alteridade das coisas que são é dita necessária à própria linguagem, quase a querer fugir do pesadelo do fr. 3 de Parmênides da identidade entre ser e

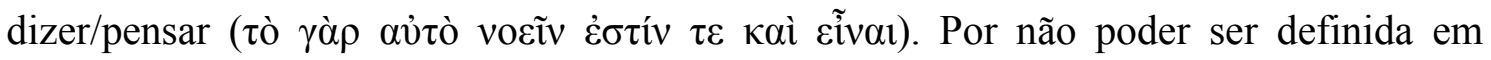
relação à unidade, ao mesmo (pois a hipótese é ainda que o Um não exista), a ginástica de Parmênides retira o termo de relação da alteridade, propondo o ò่ $\lambda \lambda \dot{\eta} \lambda \omega \nu$ ö $\lambda \lambda \alpha$, isto é, uma improvável e surpreendente definição recíproca da alteridade: os outros são outros em relação uns com os outros (164c). Tudo isso, obviamente, pela impossibilidade de sê-lo em relação ao $\mathrm{Um}^{5}$. A alteridade definida sem alguma referência à unidade significa também - e esta é a próxima passagem lógica - que esta alteridade somente pode ser dita/pensada como pluralidade $(\pi \lambda \eta ́ \theta 0 \varsigma)$ com relação a uma pluralidade (MIGLIORI, 2004, p.344). Esta dedução obriga à elaboração de uma descrição paradoxal da realidade como pura multiplicidade:

Logo, cada aglomerado destas é ilimitado por pluralidade, e mesmo que se tome a parte que pareça mínima, como um sonho no sono, de repente aparece como sendo muitas coisas em vez que um, e enorme em vez que mínimo, quando visto com relação aos fragmentos que deste derivam. (Parm.164d)

Sigo aqui a proposta de tradução de Ferrari (2004, p.357) que opta por traduzir ö $\gamma \kappa о \varsigma$ por "aglomerado", ainda que também a tradução por "conjunto" (insieme) de Migliori (1990) vai no mesmo sentido de destacar a multiplicidade que está subjacente à passagem. Ainda que Cornford tenha razão quando afirma que "the word 'mass' or 'bulk' is also used, for lack of any better term to describe quantitativeness where there is no definite quantity" (1939, p. 237), prefiro a tradução de Ferrari, que é também o caso da tradução brasileira de Iglesias (2003), pois "massa", se tem a vantagem de remeter imediatamente para uma leitura mais física da imagem, peca todavia por perder o

\footnotetext{
${ }^{5}$ É evidente que nossa página pressupõe a pagina $157 \mathrm{~b}$, que define o fato do Um ser e agir como limite (cf. CORNFORD, 1939, p. 236).
} 
sentido da multiplicidade que o termo aglomerado consegue manter com maior precisão - e que, a meu ver, é essencial na economia da dedução.

O problema aqui é ainda conseguir falar de algo tão paradoxal como seria uma quantidade não quantificável. Para isso, Platão introduz a imagem do sonho, que obedece, em grande parte, a meu ver, diretamente à necessidade de evocar esta

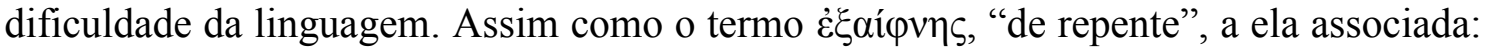
trata-se de um termo bastante significativo, que aparece no diálogo somente aqui, se se deixa de fora a passagem teoreticamente central, dedicada à própria definição do termo, em 155e-157b. Ao mesmo tempo, a página que examinamos é fortemente marcada pela aparência (falsa) da unidade (pois o Um não é):

Haverá muitos aglomerados, portanto, e cada um deles parecerá ser um, ainda que não o seja, pois o Um não é. (Parm.164d)

O léxico do "parecer", fundamentalmente ligado ao verbo phaino, que percorre esta página, alcança seu ponto alto na definição desta dedução do pensamento como phantasma: a igualdade entre os aglomerados é somente aparente, pois profundamente instável, enquanto não havendo Um não poderá haver número e quantidade, ainda que haja certa ilusão disso.

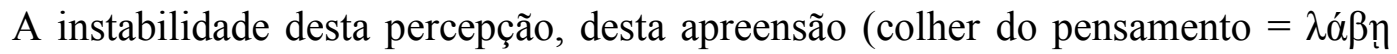

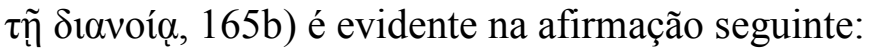

É necessário que tudo aquilo que se apreende com o pensamento, em migalhas, seja despedaçado; pois apreende-se sempre um aglomerado sem unidade. (Parm.165b)

A deriva epistêmica descrita é, finalmente, comparada àquela de um observador distante que, ao olhar para uma cena pintada à distância, parece-lhe uma; no entanto, ao ver mais de perto, pode observar que, ao contrário da unidade anteriormente "vista", aquela aparece agora "ilimitada por pluralidade" ( $\pi \lambda \eta \dot{\eta} \theta \varepsilon \iota ~ \alpha ँ \pi \varepsilon \iota \rho o v)$.

Recolhi, até aqui, quatro indícios que marcam o proceder da gymnasia: a referência ao sonho, a menção ao advérbio غ̇ $\alpha_{\alpha i ́} \varphi v \eta \varsigma$, a significativa presença do léxico de phaino e phantasma, e a imagem de um observador distante. Os quatro indícios compõem um quadro hermenêutico que tentarei aqui esboçar por grandes linhas.

O sonho é certamente a imagem que mais se destaca por sua força. Platão a utiliza com certa generosidade, até porque o sonho já havia se tornado um topos filosófico pelo 
menos desde Heráclito. Em Platão, a metáfora do sonho é comumente utilizada, de fato, para indicar um estado mental do ser humano ${ }^{6}$. Mas um estado mental que é marcado pela troca sistemática entre o que parece e o que é (R. 476c; Teet. 158a-c; $R .518 \mathrm{c})$ ou pelo fato de não conseguir levar a uma avaliação mais precisa de suas intuições, ainda que haja de fato algum tipo de apreensão intuitiva da realidade (como veremos será o caso de $R$. VII 533b-c). Esta apreensão é sempre instável e insegura, como aparece no Mênon 85c, na ocasião em que Sócrates indica que as opiniões que o escravo conseguiu juntar para realizar a demonstração da anamnese foram geradas nele, como em um sonho.

Assim, o sonho evocado por Parmênides pode ser comparado com certo proveito hermenêutico com mais duas passagens do mesmo corpus: trata-se de Teet. 201d e a página 533 do livro VII de República. Em Teet. 201d, Sócrates oferece a Teeteto um "sonho em troca de um sonho":

"SOCR. Escuta então aqui um sonho em troca de outro sonho. Pareceume ter ouvido alguém dizer que os primeiros elementos ( $\sigma \tau$ ¿oıєĩ $\alpha$ ), por assim dizer, dos quais nos e todas as coisas somos feitos, não teriam explicação $(\lambda o ́$ yov). Que cada um deles em si e por si poderia ser somente nomeado, mas que é impossível dizer qualquer outra coisa, nem mesmo dizendo que é o que não é (Teet. 201d-e).”

A passagem do Teeteto utiliza também uma hipótese negativa ("mesmo dizendo que é o que não é”), para fazer ecoar a tese (provavelmente de Antístenes) sobre a impossibilidade de conhecer os princípios da realidade. O âmbito teorético é muito próximo, portanto, especialmente quando se pensa na insistência sobre a impossibilidade da predicação de "qualquer outra coisa" (Cf. Burnyeat 1970). Esta mesma impossibilidade de predicação é consequência, na página do Parmênides que estamos analisando, da hipótese pela qual “o Um não é”. Assumimos aqui esta insistência como paralela àquela do "sonho" de Sócrates no Teeteto pelo qual os princípios seriam incognoscíveis. Em ambos os casos, de fato, o sonho representa uma hipótese negativa.

\footnotetext{
${ }^{6}$ Cf. TIGNER (1970) para as referências completas.
} 
Ainda mais interessante é a comparação com a página de República (533b). Estamos no contexto da definição do método dialético como único que alcança o sucesso da episteme, pois é o único que elimina o caráter hipotético das premissas (R.VII 533c). Aqui os geômetras e afins são chamados de "sonâmbulos do ser":

Quanto às restantes [technai], que captam uma parte do que é, isto é a geometria e seus saberes conexos, vemos que sonham sobre o que é, mas é para eles impossível vê-lo claramente, enquanto utilizam hipóteses que não discutem,

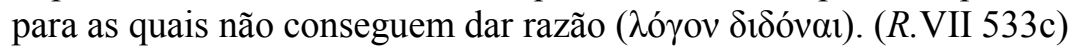

Aqui o sonho é causa da opacidade da visão sobre o que é, que resulta de uma impossibilidade de dar razão às hipóteses de trabalho da geometria. Ora, mas este "dar razão destas hipóteses" coincide com o próprio treinamento (pelo menos em seu lado negativo) que Parmênides propõe em toda a segunda parte do diálogo Parmênides $(135 c-136 a)$.

Por outro lado, que ao sonho corresponda uma suspensão da percepção normal

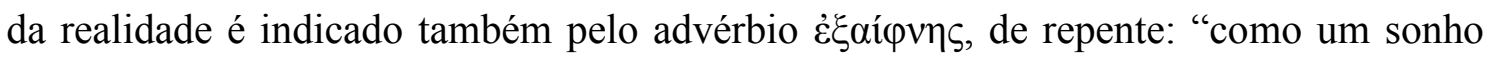
no sono, de repente." - reza a passagem acima citada (velut in somno somnium repente, é a elegante tradução de Marsílio Ficino). Como vimos, o termo aparece somente aqui em todo o diálogo, para além da passagem central de $155 \mathrm{e}-157 \mathrm{~b}$, onde o advérbio

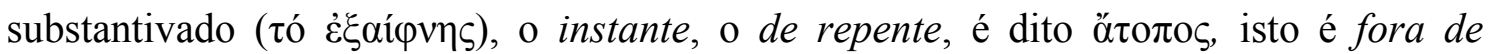
qualquer determinação espacial (156d), pois encontra-se num lugar intermediário

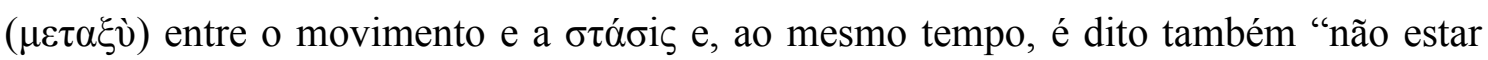

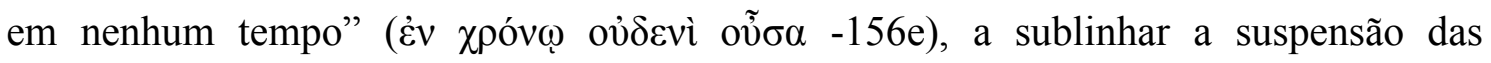
coordenadas normais da percepção, exatamente como num sonho.

Veremos a seguir qual pode ser o sentido desta específica insistência no sonho.

Antes, é o caso de voltar ao conteúdo deste sonho e, mais em geral, da passagem H2D3: é sonho de uma realidade "à deriva" na pura multiplicidade, é o pesadelo - é o caso de dizer - de um mundo em contínua fragmentação de aglomerados sem Um. O

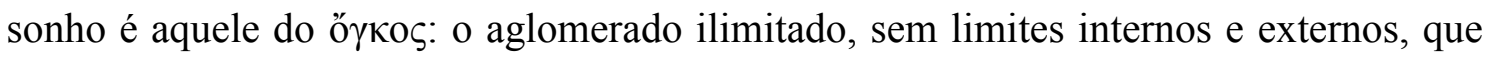
somente parece um, mas não o é (164d). Há um pesadelo após o sonho, portanto, pois ao amargo despertar de uma onírica aparência de unidade, ou melhor, de uma sonhada individuação dos entes, segue o pesadelo (vívido, ainda que em hipótese) de um mundo sem limites: 
Assim parecerá que há um número destes [aglomerados], se de fato cada um é um e são muitos. - Certamente -. E que nele parece haver pares e ímpares, mas sem que isso seja verdade, pois o Um não é. (Parm.164d-e)

O número faz aqui sua esperada aparição, por se tratar de uma discussão entre unidade e multiplicidade, mas a introdução da dupla par e ímpar não é exatamente esperada, e parece apontar para uma referencia bastante específica, ainda mais quando vista no contexto da dupla ilimitado-limitado, que marca esta página. "Ter número" e ter neles "o par e o ímpar" remete diretamente para um diálogo com as tradições pitagóricas de segunda geração, por assim dizer, e notadamente com Filolau.

Que Platão conhecesse bem o trabalho de Filolau é comprovado por diversos testemunhos que o acusavam de plágio deste e que, ainda que provavelmente improcedentes, revelam ao menos que os textos deste pitagórico circulavam em Atenas no início do século IV (Brisson, 2000, p.35-45; Cornelli, 2011). Dediquei uma ampla seção de meu recente livro sobre o pitagorismo (Cornelli, 2011) para discutir a autenticidade da maioria dos fragmentos de Filolau.

Mas é especialmente uma passagem central da Metafísica de Aristóteles que autoriza esta afirmação de uma origem pitagórica do conteúdo do sonho de Parmênides em H2D3. Os pitagóricos, de fato,

Afirmam como elementos constitutivos do número o par e o ímpar; dos quais o primeiro é ilimitado e o segundo limitado. O Um deriva de ambos os elementos, porque é par e ímpar ao mesmo tempo. Do Um procede depois o número; e os números, como dissemos, constituiriam a totalidade do universo. (Metaph. 986a 17-21)

Essa derivação faz sim que o Um seja ao mesmo tempo par e ímpar e, como tal, princípio dos números. Aqui, os dois princípios são o par e o ímpar, enquanto limitado e ilimitado parecem ser somente atributos destes. Aristóteles explica essa correspondência entre par e limitado de um lado, e ímpar e ilimitado do outro, em uma difícil passagem da Física (203a). A mesma ideia reaparece também em seu fr. 199 (Rose), provavelmente extraído de um de seus livros sobre os pitagóricos, e encontra um eco significativo na ideia do artiopéritton, o "parímpar", do fr. 5 de Filolau que veremos a seguir.

Outra passagem da mesma Metafísica segue de perto os termos do raciocínio hipotético da página do Parmênides que estamos estudando, notadamente na questão da individuação pela limitação: 
De fato, eles afirmam claramente que, uma vez constituído o Um seja com planos, com cores, com sementes, com elementos dificilmente definíveis -, imediatamente, a parte do ilimitado que lhe era mais próxima começou a ser atraída e delimitada pelo limite. (Metaph. 1091a15-18)

Darei aqui por aceito - pois procurei demonstrar isso, na esteira de Huffman (1993), em outro lugar - que quando Aristóteles fala dos pitagóricos está, de fato, se referindo a Filolau. Não será o caso aqui de avaliar todos os fragmentos, mas sim de mostrar como há uma instigante correspondência lexical e teorética entre esta página do Parmênides e o que nos resta do livro de Filolau.

O fragmento 3 de Filolau parece revelar o mesmo tom epistêmico (baseado na negação da predicação e do conhecimento) que encontramos na página do Parmênides: "De maneira alguma seria possível conhecer algo, se todas as coisas fossem ilimitadas" (44 B3 DK). O limitar, que como vimos acima nas citações de Metaph., seria a função do Um, é o que permite o conhecer. No sonho em que o "Um não é”, portanto, "de maneira alguma é possível conhecer algo", diria Parmênides, como que parafraseando Filolau.

No mesmo sentido, o fr. 4 de Filolau indica qual devia ser o papel dos números nesta sua epistemologia, por assim dizer:

E, de verdade, todas as coisas que são conhecidas têm número. Pois desta forma não é possível que alguma coisa seja pensada ou conhecida sem este. (44 B4 DK)

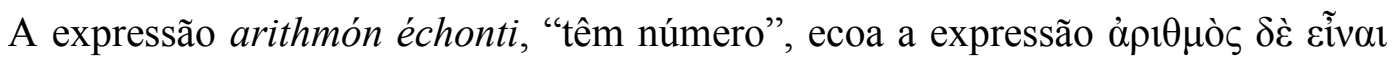

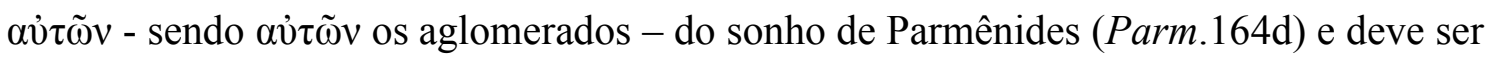
compreendida, no rastro da ideia grega dos arithmoi como pluralidade ordenada, no sentido de que a realidade é constituída por uma pluralidade ordenada.

Duas anotações são aqui importantes: a) a segunda parte do fragmento não parece deixar dúvidas em relação a qual deveria ser o papel dos números em Filolau. A função destes é precisamente epistemológica: graças ao fato de a realidade "ter número" é que

\footnotetext{
${ }^{7}$ Timpanaro Cardini (1958-62, III, p. 154) anota - com relação a esta passagem aristotélica - que poderia tratar-se aqui de um achado aristotélico de diversas doutrinas que eram desenvolvidas pelo pitagorismo antigo para explicar como era formado o Um.
} 
ela pode ser conhecida, enquanto é passível de uma descrição numérica; b) não é inútil aqui anotar que os números respondem diretamente às exigências epistemológicas parmenídicas, as mesmas que no Poema são postas como "sinais" no caminho do ser (28 B8 DK): para que possa haver conhecimento, o objeto deverá ser ingênito, eterno etc. Em suma, algo limitado. Todavia, Filolau, desejoso de fugir da imobilidade do ser eleático, introduz os números como solução para manter, de um lado a pluralidade, do outro a determinação do ser (Huffman, 1993, p.67).

Que o número possa ser considerado como sinal (à maneira de Parmênides) do ser das coisas que são é o que sugere o fr. 5, que utiliza exatamente o verbo semaíno para descrever como a realidade expressa os números:

O número possui duas espécies que lhe são próprias: o ímpar e o par; a terceira, resultante da mistura de ambos, é o parímpar. De cada uma das duas espécies existem muitas formas, das quais cada coisa enquanto tal dá sinais. (44 B5 DK)

O fr. 5 introduz os mesmos termos "par" e "ímpar" (além do "parímpar", o

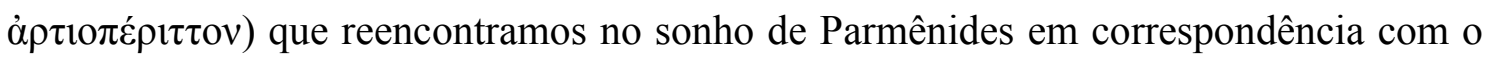
ilimitado-limitado. Esta correspondência é sugerida também pelo próprio Aristóteles, conforme foi antecipado acima, quando propõe uma direta correspondência entre as duas duplas. Aristóteles explicita mais precisamente o sentido dessa correspondência entre par e limitado e ímpar e ilimitado na Física (203a):

Para eles [os pitagóricos], o ilimitado é o número par. Este, de fato, quando interceptado e limitado pelo ímpar, torna presente a indeterminação aos entes. Sinal disso é o que acontece com os números; de fato, conforme sejam colocados ou menos os gnômons em torno ao um, a espécie (do número) permanece uma só ou, ao contrário, torna-se sempre diferente. (Phys. 203a $=58$ B28 DK)

A explicação aristotélica pode ser facilmente visualizada a partir do momento em que se utilize a aritmética dos pséphoi de Eurito, que não acaso é considerado, pela doxografia, discípulo de Filolau (D.L. Vitae III. 6; VII. 46). Colocando de fato um gnómon, um esquadro para desenhar ângulos retos, em volta do um ou do dois, respectivamente, resultam duas séries diferentes de números: os pares e os ímpares. $\mathrm{O}$ esquadro que circunscreve o um irá sempre interceptar números ímpares, resultando sempre em figuras quadradas. O esquadro que circunscreve os números pares, ao contrário, irá sempre desenhar retângulos, isto é, figuras geométricas de lados sempre diferentes, conforme a figura abaixo: 

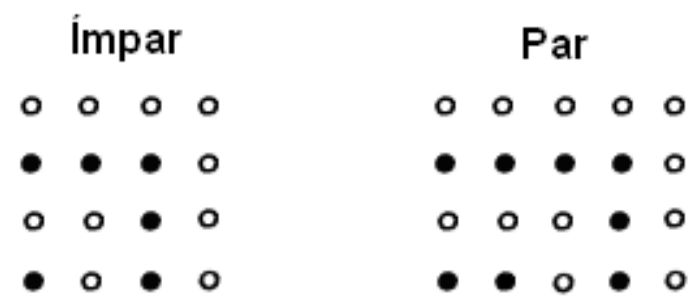

O testemunho de Física 203a acaba confirmando a autenticidade de certa correspondência, em Filolau, entre os princípios ilimitados/limitados e os números: a mesma que encontramos desenhada na página H2D3 do Parmênides.

Não deixa obviamente de interessar a anotação de Cornford pela qual o próprio

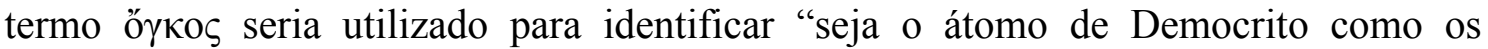
átomos-pontos dos pitagóricos" (1939, p.241), isto é, os psephoi. Os aglomerados sonhados poderiam ser, na verdade, as próprias pedrinhas pitagóricas de Eurito. Não por acaso, na página do Parmênides em questão, a estes aglomerados são atribuídos números e, de maneira especial, o par e o ímpar. A referência à aritmo-geometria pitagórica seria aqui implícita.

Em suma, a realidade mesma é de fato constituída por coisas limitantes e coisas ilimitadas, das quais os números podem ser considerados sinais.

É o que afirmam os últimos dois fragmentos que examinaremos: os fragmentos 1 e 2 .

A obra Sobre a Natureza iniciava com a seguinte afirmação: a natureza no ordenamento do mundo resultou do acordo de coisas ilimitadas e limitantes, e assim o inteiro cosmos e todas as coisas que estão nele. (44B1 DK)

O mesmo se diz no fr. 2, que, utilizando a mesma terminologia do "acordo" de "ilimitados/limitantes" do fr. 1, explicita mais claramente qual devia ser o alcance dessa teoria:

De Filolau, sobre o ordenamento do mundo: necessariamente as coisas que são devem ser todas ou ilimitadas ou limitantes, ou ilimitadas ou limitantes ao mesmo tempo; limitantes somente, porém, ou somente ilimitadas não poderiam ser; considerando que mostram evidentemente serem as coisas nem todas limitantes nem todas ilimitadas, é claro, portanto, que, do acordo de limitantes e ilimitados, tanto o ordenamento do mundo quanto as coisas nele resultaram. É demonstrado pelos fatos que as coisas que derivam dos limitantes limitam, e que as que derivam dos limitantes e ilimitados limitam ou 
não limitam, e que aquelas que derivam dos ilimitados parecem ilimitadas. (44 B2 DK)

Aqui está obviamente prefigurada a díada platônica: este fragmento serve de base para o Filebo 16c e pode contribuir a provar que Aristóteles tem razão a falar de uma forte influência pitagórica sobre Platão ${ }^{8}$. A própria expressão $\dot{\alpha} \lambda \lambda \hat{\eta} \lambda \omega \nu$ $\alpha \lambda \lambda \lambda \alpha$ acima citada, central para a dedução da página do Parmênides (na ausência de unidade, isto é, do limite, podemos somente afirmar que o grande é maior do que o pequeno, e assim em diante), dá razão a Cornford (1939, p.236) e remete para o conceito da díada, como o continuum grande-pequeno descrito no Filebo (24).

Não é improvável que possa haver um diálogo menos evidente, e ainda assim bastante significativo, neste último fr. 2 , com a imagem do sonho e com próprio sentido da gymnasia na segunda parte do Parmênides.

Refiro-me propriamente ao ritmo do fr. 2. A ladainha dos limitantes/ ilimitados lembra de perto um estilo encantatório. Este seria certamente um sinal, do profundo enraizamento do texto filolaico no contexto da produção filosófica pré-socrática. Burkert (1972, p.252 n.67) cita os fragmentos 6 de Anaxágoras e 8 de Parmênides como exemplos desse mesmo estilo. Podemos pensar, por exemplo, no mesmo ambiente onírico desenhado no Proêmio do Poema de Parmênides. A expressão das ideias assume aqui conotações encantatórias performáticas: é como se a repetição da harmonia entre limitantes e ilimitados quisesse fazer ecoar nas palavras o som dessa mesma harmonia, tornando-a assim presente, pela força das palavras. O fragmento, de certa forma, pede para ser ouvido em seu ritmos e sonoridade próprios. Esse estilo quase oracular insere o texto filolaico também na tradição esotérica pitagórica (e não somente pitagórica), bem descrita por Gemelli Marciano:

Nos textos esotéricos de Heráclito, Parmênides, Empédocles, a recepção dos mýthoi e dos lógoi é expressa unicamente pelo verbo akồein, ouvir. Que não seja simplesmente a reprodução artificial de uma situação de transmissão oral, mas de uma situação efetiva, resulta especialmente evidente no momento em que a palavra é expressamente definida como uma entidade física que penetra no corpo provocando mutações. $\mathrm{O}$ poder de ação e de transformação exercido pela palavra em sua fisicidade é, por outro lado, o elemento fundamental dos encantamentos e das fórmulas mágicas, como Górgias testemunha explicitamente em seu Elogio de Helena (GEMELLI MARCIANO, 2007, p. 449-450).

\footnotetext{
${ }^{8}$ A esta questão dediquei um artigo recentemente (Cornelli, 2010).
} 
Minha hipótese de trabalho é que esta mesma dimensão onírica e encantatória se revelaria na segunda parte do Parmênides: os indícios acima levantados podem ser lidos

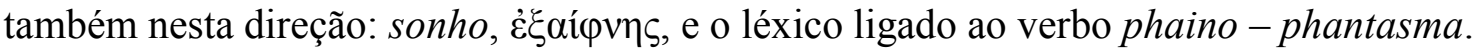

Assim, os paradoxos da segunda parte do Parmênides seriam mais do que exercícios lógicos: ao contrário, podem ser pensados como maneiras de puxar o tapete dos automatismos de nosso pensamento, isto é, de um olhar demasiadamente acostumado a olhar para a multiplicidade, sem colher a outra ponta, indispensável, do continuum da díada: isto é, a unidade. O sonho (no sono!) seria uma ótima imagem, diria quase heraclítica, para falar deste automatismos e do necessário treinamento (gymnasia) para fazer a experiência do que é. Trata-se de uma prática central da tradição eleático-pitagórica. Não uma competição lógica, portanto, um jogo para acadêmicos nerds - como, de certa maneira, a tradição platônica e aristotélica quis nos fazer ver - mas sim um processo educativo negativo, de desconstrução do olhar, de libertação, de purificação do pensamento pela apresentação de aporias.

Se se tratasse de logical enquiries, como afirmava Gilbert Ryle (1939, p. 316), o sentido de lógico precisaria ser posto noutra perspectiva: certamente no interior do sentido platônico de gymnasia geométricas, não no sentido redutivo que a abordagem analítica tem pregado; mas também na tradição pitagórico-eleática que está explicitamente por trás destas páginas do Parmênides ${ }^{9}$. A coleção de puzzles da segunda parte do Parmênides, portanto, mais do que "entregue [para a diversão] de neoplatônicos ou de filósofos analíticos entusiasmados" (Mccabe, 2000, loc. 94) são parte de um projeto acadêmico maior.

Deste ponto de vista, não é novamente o caso de escolher entre uma função lógica e outra metafísica dos paradoxos (Cf. Ferrari, 2004, p.129), pois o processo educativo negativo dos paradoxos é a preparação para a abertura da mente para colher o que é": exatamente como nos paradoxos de Zenão, discípulo de Parmênides (e não de Frege), e, em segunda geração, de Amínias, o pitagórico. Os números e o limite são coisa séria, do ponto de vista existencial e ontológico, no interior desta tradição itálica.

\footnotetext{
${ }^{9} \mathrm{O}$ treinamento das hipóteses negativas é explicitamente referido a Zenão na página 135c-136a, "se quer

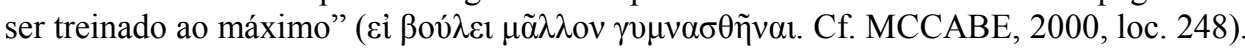


É neste sentido, creio, que será possível pensar nas hipóteses do Parmênides como em algo teoreticamente relevante, e não um simples jogo, ou pior, como quiseram alguns, uma ironia ou uma paródia do monismo eleata. Houve até quem suspeitou de certo autolesionismo nihilista, como é o caso de Calogero (1984, p.420) que fala da mais "colossal autodestruição dos conceitos que foi jamais registrada na história do pensamento" $"$.

Assim, se esta gymnasia tem algo a ver com a desautomatização do pensamento, então a própria aporia com a qual se conclui a segunda parte do Parmênides pode ser considerada como parte essencial desta estratégia pedagógico-existencial do paradoxo.

Em suma, e esta é minha sugestão de leitura, o sonho de Parmênides e os indícios a ele correlatos de derivação da passagem H2D3 da tradição pitagórica, podem ser uma chave para compreender este "mecanismo realmente infernal" da segunda parte do diálogo (Ferrari, 2004, p.119) em sentido menos lógico, e mais próximo do modus operandi da filosofia itálica com a qual Platão estava querendo dialogar explicitamente.

\section{REFERÊNCIAS BIBLIOGRÁFICAS}

BURNYEAT, M. F. The Material and Sources of Plato's Dream. IN: Phronesis: A Journal for Ancient Philosophy, 15, 101-122, 1970.

BRISSON, L. Lectures de Platon. Paris: Librairie Philosophique J. Vrin, 2000 (ed. bras. Leituras de Platão, trad. Sonia Maria Maciel. Edipucrs, Porto Alegre).

CALOGERO, G. Scritti minori di filosofia antica. Napoli: Bibliopolis, 1984.

CHERNISS, H. The riddle of the early academy. Berkeley: University of California Press, 1945.

CORNELli, G. O pitagorismo como categoria historiográfica. Coimbra/São Paulo: Annablume/Imprensa da Universidade de Coimbra, 2011.

CORNELLI, G. Una metafisica pitagorica nel Filebo?. IN: Methexis XXIII, 35-52, 2010 .

CORNELli, G. A. Academia de Atenas no tempo de Platão como lugar de ausências. In: SOARES, C.; CASADESUS BORDOY, F. \& FIALHO, M. do Céu (eds.). Redes

\footnotetext{
${ }^{10}$ Cf. FRONTEROTTA (1998, p.14-16) para as citações.
} 
Culturais nos Primórdios da Europa - 2400 Anos da Fundação da Academia de Platão. Imprensa da Universidade de Coimbra, Coimbra, p. 69-85, 2016.

CORNFORD, F. Plato and Parmenides: Parmenides' Way of truth and Plato's Parmenides. London: Kegan Paul/ Trench, Trübner, 1939.

DILLON, J. The heirs of Plato: a study of the Old Academy (347-274 B.C.). Oxford: Clarendon Press, 2003.

ERLER, M. Platão. São Paulo/Brasília: Colecção Archai, Annablume Clássica/Editora da Universidade de Brasília, 2012.

FERRARI, F. Parmenide. Milano: BUR, 2004.

FRONTEROTTA, F. Guida alla lettura del Parmenide di Platone. Roma: Laterza, 1998.

GEMELLI, M. L. M. Die Vorsokratiker. Band I. Artemis \& Winkler, Düsseldorf, 2007. HUFFMAN, C.A. Philolaus of Croton: Pythagorean and Presocratic. A Commentary on the Fragments and Testimonia with Interpretive Essays. Cambridge University Press, Cambridge, 1993.

IGLESIAS, M. Parmênides. São Paulo: Loyola, 2003.

ISNARDI-PARENTE, M. Studi sull'Accademia platonica antica. Firenze: Olschki, 1979.

ISNARDI-PARENTE, M. = Speusippo, Frammenti, a cura di M. Isnardi Parente. Napoli: Bibliopolis, 1980.

ISNARDI-PARENTE, M. = Senocrate-Ermodoro, Frammenti, a cura di M. Isnardi Parente. Napoli: Bibliopolis, 1982.

MCCABE, M. M. Unity in the Parmenides. In: GILL, C. \& MCCABE, M. M. (eds.). Form and Argument in Late Plato. Oxford: Oxford University Press [Kindle version], 2000 .

MigliORI, M. Dialettica e verità: Commentario filosofico al Parmenide di Platone. Milano: Vita e Pensiero, 1990.

MORAVCSIK, J. Plato and Platonism: Plato's conception of appearance and reality in ontology, epistemology, and ethics, and its modern echoes. Oxford: Blackwell, 1992.

RYLE, G. Plato’s Parmenides. IN: Mind 48 (190), 129-151, 1939.

TIGNER, S. Plato's Philosophical Uses of the Dream Metaphor. IN: The American Journal of Philology 91(2), 204-212, 1970. 